\title{
Identity, larva and distribution of the Oriental soldier fly, Odontomyia ochropa (Diptera: Stratiomyidae)
}

\author{
JANA NERUDOVÁ-HORSÁKOVÁ ${ }^{1}$, DAmIR KOVAC ${ }^{2}$ and RudOLF ROZKOŠNÝ ${ }^{1}$ \\ ${ }^{1}$ Department of Zoology and Ecology, Faculty of Science, Masaryk University, Kotlářská 2, 61137 Brno, Czech Republic; \\ e-mail: j.nerudova@centrum.cz; rozk@sci.muni.cz \\ ${ }^{2}$ Forschungsinstitut Senckenberg, Senckenberganlage 25, 60325 Frankfurt am Main, Germany; \\ e-mail: damir.kovac@senckenberg.de
}

Key words. Stratiomyidae, Odontomyia ochropa, adults, larvae, Oriental region, taxonomy, morphology

\begin{abstract}
Odontomyia ochropa Thomson, 1869, is redescribed and found to be identical with O. dorsoangulata Brunetti, 1920, which is proposed as a new synonym. The female holotype of $O$. ochropa from the Philippines was examined and compared with specimens from India, Thailand and Singapore. Terminalia and other diagnostic characters of both sexes are illustrated. The larva of $O$. ochropa is described in detail. The larval characters are in accordance with the characters of $O$. dorsoangulata mentioned by Brunetti (1920). The larva of $O$. ochropa is compared with that of $O$. cyanea described by Mathur (1933). Cuticular structures and diagnostic characters of both larvae are documented by drawings and SEM micrographs. A new identification key to larvae of Odontomyia known from the Oriental Region is provided.
\end{abstract}

\section{INTRODUCTION}

According to Woodley (2001) there are 215 species of Odontomyia Meigen, 1803 worldwide, 25 of which are recorded from the Oriental Region. Nevertheless, the majority of these species are poorly known and need a modern taxonomic revision. Brunetti (1923) published an identification key to 34 "Oriental" species, but 10 of them, according to present knowledge, occur only in the Australasian Region. Three of Brunetti's “Oriental species of "Odontomyia" belong in the genus Oplodontha Rondani, 1863 and one to the genus Afrodontomyia James, 1940. Later, two additional Oriental Odontomyia species were described by E. Lindner: O. quadrata (Lindner, 1937) from southern India and $O$. bipunctifacies (Lindner, 1951) from Sumba (Indonesia). Recently, Rozkošný \& Kovac (1994) described a new species, O. latitibia, from East Malaysia.

Odontomyia ochropa Thomson, 1869 is a little known species described from the Philippines. We compared its holotype with the widespread $O$. dorsoangulata Brunetti, 1920 , and came to the conclusion that both nominal species are identical. $O$. ochropa is thus redescribed here and the terminalia of both sexes are illustrated for the first time.

Odontomyia larvae are chiefly aquatic and develop mainly in stagnant waters although some of them can also live in the shallow margins of slow-running waters (Mathur, 1933). Pools, ponds, lakes and tree holes filled with water are common larval habitats. The larvae of $O$. latitibia have been found in bamboo phytotelmata (Rozkošný \& Kovac, 1994) and recently also in water-filled cavities in fallen trees in North Thailand (recent observation by D. Kovac). O. pulcherrima larvae occur on wet rocks at waterfalls (Rozkošný \& Kovac, 2001) and $O$. cyanea larvae in rock-pools on river banks (recent observation by D. Kovac). The Odontomyia larvae possess a subconical or almost oblong anal segment, which is only rarely elongated, forming a more or less distinct breathing tube. All the known larvae of this genus have a welldeveloped apical coronet of pinnate setae and pairs of conspicuous ventral hooks are frequently developed on the posterior margin of abdominal segment 7 (sometimes also on segments 2 and 6). Larvae of some species have ventral hooks or spines arranged in transverse rows on the posterior margins of abdominal segments 2-7. Our detailed description of the larva of Odontomyia ochropa is compared with those of other known Oriental Odontomyia species and a preliminary key to the larvae of four Oriental Odontomyia species is given. For terminology see Rozkošný (1982).

\section{MATERIAL AND METHODS}

Stratiomyid larvae were collected individually and reared to the adult stage in separate dishes that contained mud from the original locality. The substrate was moistened daily to simulate the natural conditions. The larvae and puparia were preserved in $70 \%$ ethanol. Preparation for SEM was as follows: After cleaning, larvae and puparia were preserved in $70 \%$ ethanol, dehydrated in a graded series of ethanol solutions, dried by the critical point technique with $\mathrm{CO}_{2}$, and coated with palladiumgold before observation under the scanning microscope.

The following abbreviations of institutions are used: FSMU Faculty of Science, Masaryk University, Brno, Czech Republic; KUB - Kasetsart University, Bangkok, Thailand; NHMW Naturhistorisches Museum, Wien, Austria; NHRS - Naturhistoriska Riksmuseet, Stockholm, Sweden; SMFD - Forschungsinstitut und Naturmuseum Senckenberg, Frankfurt a. M., Germany; NMSC - Zoological Reference Collection of the Raffles Museum of Biodiversity Research, National University of Singapore. 


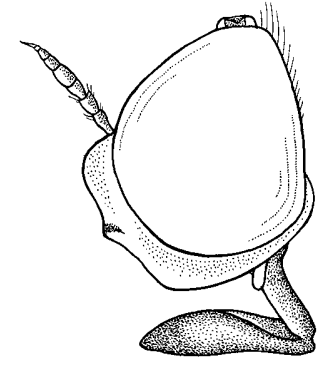

1

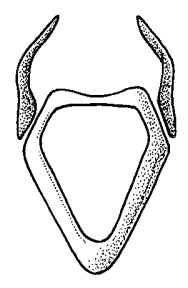

6

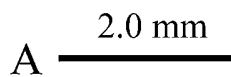

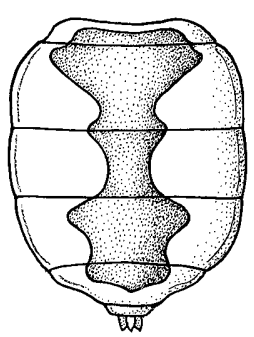

2

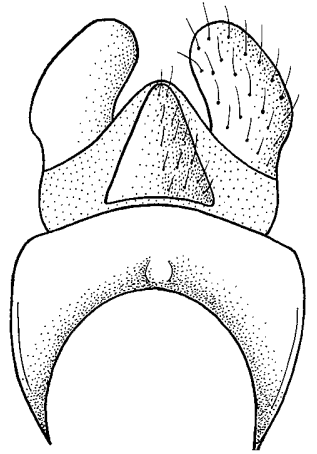

7

B $\stackrel{0.25 \mathrm{~mm}}{ }$

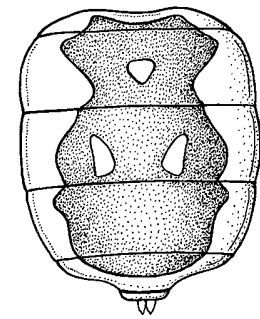

3

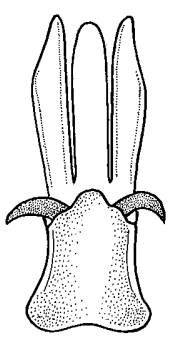

8
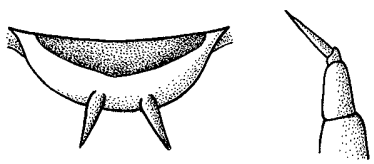

4

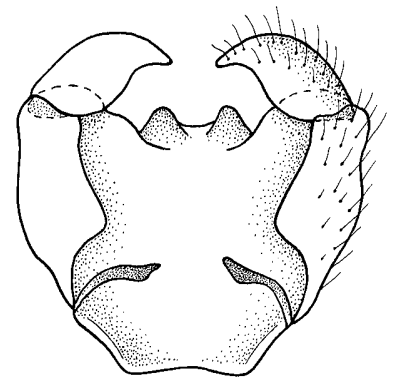

9

Figs 1-9: Odontomyia ochropa, adults. 1 - male head in lateral view; 2 - male abdomen in dorsal view; 3 - female abdomen in dorsal view; 4 - scutellum; 5 - apex of antenna; 6 - female genital furca; 7 - male epandrium, proctiger and cerci; 8 - phallic complex; 9 - genital capsule. Scales: A - (1-4); B - (5); C - (6-9).

\section{RESULTS}

\section{Odontomyia ochropa Thomson, 1869}

Odontomyia ochropa Thomson, 1869: 456.

Odontomyia dorsoangulata Brunetti, 1920: 68, syn. n.

\section{Redescription of adults}

(Figs 1-9)

Diagnosis. Resembling the Palaearctic $O$. angulata (Panzer, 1798) with largely pale frons in the female and yellow legs. The facial tubercle is relatively broad and low, and lateral parts of scutum beyond the suture as well as the upper pleura are often extensively translucent yellow in both sexes. The pale abdomen has a differently broad blackish pattern along medial third or more. The terminalia of both sexes are species-specific.

Male. Head (Fig. 1) only slightly higher than long, with a somewhat prominent lower posterior angle in profile. Large bare eyes contiguous for a distance equalling that between upper frons and anterior ocellus. Ocellar tubercle low, subtriangular, postocellar area barely as long as ocellar triangle. Upper frons, ocellar triangle, vertex and entire occiput black; lower frons above antennae and face reddish yellow to pale brown; only epistoma with a small transverse black spot. Antennae ochre yellow, sometimes brownish toward tip. Antennal index (flagellum : combined length of basal antennal segments) about 1.6-1.9; two last flagellomeres at most slightly longer than flagellomere 4; last flagellomere slender, elongate conical (Fig.
5). Proboscis pale yellow with black labellae, palpi yellow. Head pile exclusively pale and mostly inconspicuous, somewhat longer and erect only on vertex and cheeks.

Thorax chiefly black. Scutum subshiny black, finely and densely punctate, only lateral parts between suture and postalar calli often translucent yellow. Scutellum (Fig. 4) greenish yellow with a transverse semicircular black spot at base, relatively strong scutellar spines completely pale. Subscutellar upper part of mediotergite strongly swollen, whole of mediotergite and extensive inner parts of laterotergites dull black. Pleura extensively yellow on upper part (propleura above fore coxa, broad upper and posterior margin of anepisternum, posterior corner of katepisternum and outer part of laterotergite), lower part blackish. Thoracic hairs exclusively pale, whitish to golden yellow. Scutum with appressed golden yellow hairs being somewhat less dense on disc; scutellum predominantly bare, with a short whitish fringe along posterior margin. Longer and partly erect whitish hairs on notopleuron, above fore coxa, along upper pleura and outer parts of laterotergites.

Wing hyaline, veins and pterostigma pale yellow. Vein $M_{3}$ virtually absent, its short basal part being barely visible as an indistinct fold. Thoracic squama yellowish, with long marginal fringe. Halter pale brown, knob pale green. 
Legs chiefly yellow, only fore and hind coxa often blackish. Tarsi sometimes more brownish toward apices; claws usually shiny black at least the apical half. Pale hairs longer only on posterior surface of femora.

Abdomen (Fig. 2) yellow to pale green (sometimes even pale brown as a result of postmortal changes), with elongate and medialy constricted black pattern on medial third. Abdominal pile pale, mostly appressed, longer and erect only on anterolateral parts. Extensive central area of dorsal surface (overreaching black pattern) covered with short and appressed black pubescence.

Male terminalia (Figs 7-9) of the basic Odontomyia type: Epandrium relatively narrow, with both proximal corners pointed. Epiproct subtriangular and cerci stout and short. Synsternite with distinctly bilobate medial process, gonostylus curved inwards and pointed apically. Phallic complex tripartite, parameres barely longer than aedeagus.

Female. As in male except as follows: Frons occupying slightly less than middle third of head, somewhat narrower at vertex and thus narrower than one eye in dorsal view. Frons completely yellow to orange, only ocellar triangle black and facial tubercle with a brown midpatch; also anterior margin of mouth somewhat darkened. Distinct fine median groove between anterior ocellus and base of antennae. Upper frons with two shallow symmetrical depressions, lower frons with a pair of subquadrate flat calli. Postocular area very narrow but distinct along whole posterior eye margin. Lower postocular corners usually not prominent in profile. Black abdominal pattern usually broader than in male and sometimes with regular or even irregular small pale spots in the dark area (Fig. 3). Genital furca (Fig. 6) subtriangular, with comparatively narrow frame; posterior projections slender and pointed.

Length. Body 7.8-12.1 mm, wing 7.7-10.4 mm.

Material examined. Holotype of Odontomyia ochropa female labelled "Manilla", "Kinb." and "Type", in NHRS.

Additional material: INDIA: $2 \hat{\sigma}, 1 \%$, Calcutta (NHMW). THAILAND: $1 \delta^{\star}, 11 . v i i i .1963 ; 10$, Muak Lek, 3.vi.1963; 1 \% , Bangkhen, 18.viii.1963; 1 으, Bangkhen, 10.ix.1963; 1 으, Lang Suan, 30.iv.1963; (all in KUB). SINGAPORE: 10, Lim Chu Kang, duck pond, ex larva 16.i.1991 (C.M. Yang) (NMSC).

\section{Description of larva and puparium}

Mature larva

(Figs 10-20)

Shape and colour. Elongate, somewhat flattened, abdominal segments gradually tapering and elongate towards caudal. Head mostly reddish brown, only pair of longitudinal stripes along clypeofrontal lines darkened. Body segments yellowish brown in ground colour, with a not too conspicuous dark brown and yellow pattern. Thoracic segment 1 predominantly brown but paler on broad sublateral areas around prothoracic spiracles. Central third of anterior margin of thoracic segment 2 predominantly brown, other parts predominantly yellowish brown. Beginning from thoracic segment 2, there is an undulate longitudinal stripe more or less distinct on each side of middle third of segments. Pattern on thoracic segment 3 similar to previous segment but undulating stripes on sides of central third narrower. Similar pattern, more or less distinct, visible on posterior margin of abdominal segments 2-7. Second and third thoracic segment with incomplete pale dorsal midline.

Dorsolateral ornamentation consisting of contrasting dark, brown and chiefly oval cuticular plates, which are being larger than other cuticular cells. Ornamentation developed chiefly in sublateral depressions of each thoracic and abdominal segment. Some isolated oval dark plates also visible on central area and along posterior margins of segments. Sublateral groups of plates arranged in one convex line on thoracic segment 1 , and in two irregular lines on thoracic segments 2 and 3. Abdominal segments adorned with numerous (20-28) dark brown cuticular plates forming a characteristic pattern on each sublateral area. Anal segment with a pair of dorsomedian lines and a pair of sublateral lines. Ventral side almost uniformly yellowish brown, but paler incomplete median stripe occupying middle third of abdominal segments 5 and 6. Again all segments with ornamentation in sublateral parts consisting of dark oval cuticular plates, their arrangement in longitudinal lines being distinct on body segments 5-8.

Head (Figs $10-12 ; 15-19)$ partly retracted into thoracic segment 1 , only slightly longer than wide in dorsal view, head index (length: width) 1.0-1.3. Labrum, as a prolongation of clypeus, somewhat longer than anterolateral corners of head capsule. Eyes convex, in dorsolateral position; antennae (a, Fig. 15) placed subapically on anterolateral corners of head capsule. Basal segment of antenna about four times as long as wide; apical segment short, conical. One, short distinct subcylindrical sensilla at base of apical segment (see, Fig. 19). Mouthparts arranged as in other known Odontomyia larvae (Rozkošný \& Kovac, 1994, 2001). Longitudinal genal lobes with dense fringe of hairs. Mandibular-maxillary complex densely haired, with more or less distinct transverse rows of flat setae, finger-like maxillary palpus relatively long. Ventral opening of head capsule well developed, covered with fine membrane. Anterior margin of ventral opening with a central tuft of hairs.

Body segments. Larval body consisting of three thoracic and eight abdominal segments. Abdominal segments gradually tapering and elongated towards distal end. No intersegmental projections and no sternal patches found. 8-12 more or less distinct ventral spines developed on posterior margin of abdominal segments 1-7 (Figs 14, $20)$. Spines on abdominal segment 1 only small or even missing; spines on following abdominal segments becoming longer and stouter towards anal segment, submedian pair being usually longer and stouter, and apparently identical to the so-called ventral hooks developed on posterior margin of segment 7 in many other larvae of the genus. Similar rows of spines along posterior margin of abdominal segments also developed on dorsal surface (Fig. 13), but spinules often only small to indistinct (especially on segments 1-2). Anal segment (Figs 13,14) comparatively long (index, i.e. length : width at base, 2-2.5), slightly tapering towards posterolateral corners. Longitu- 

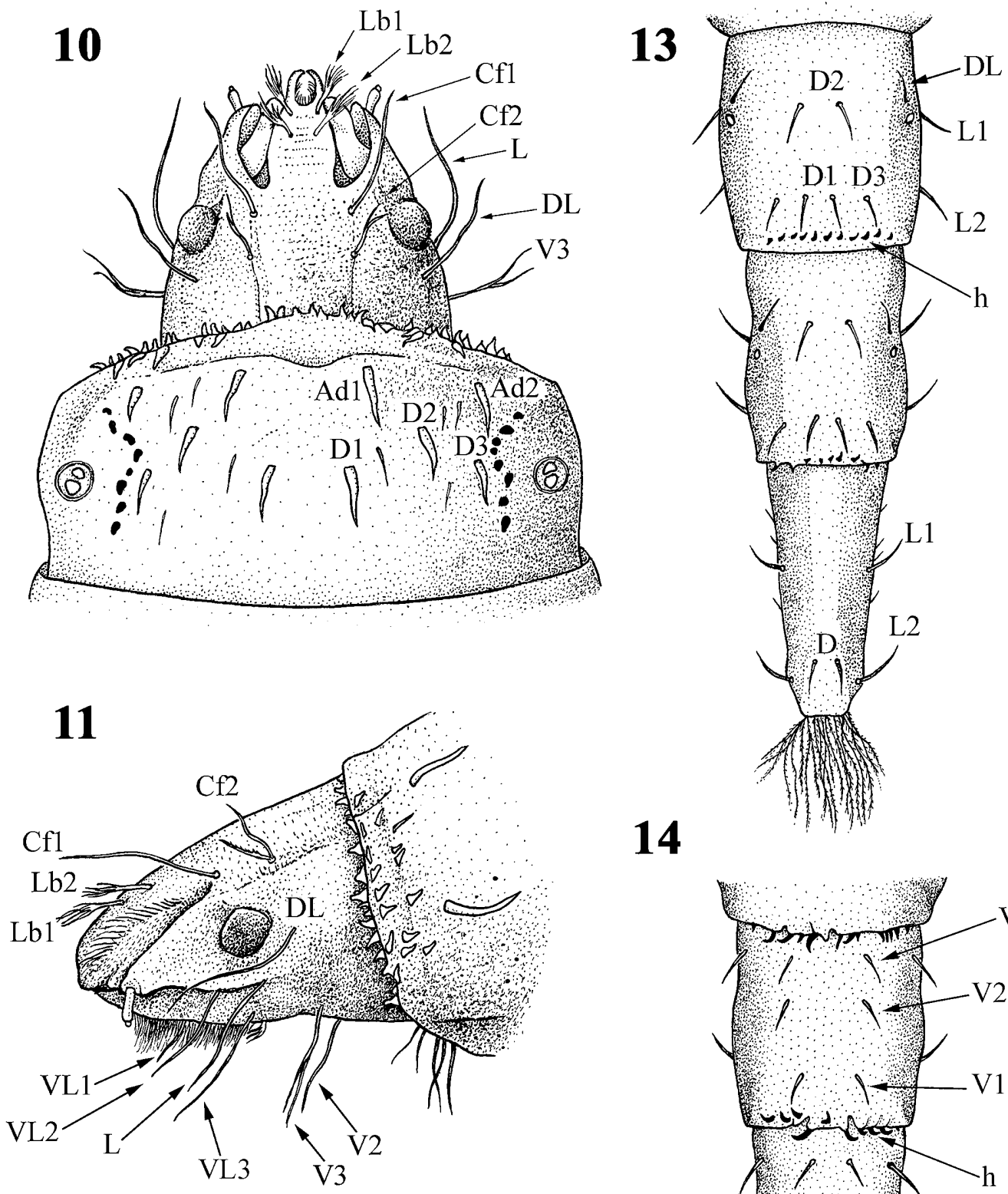

14

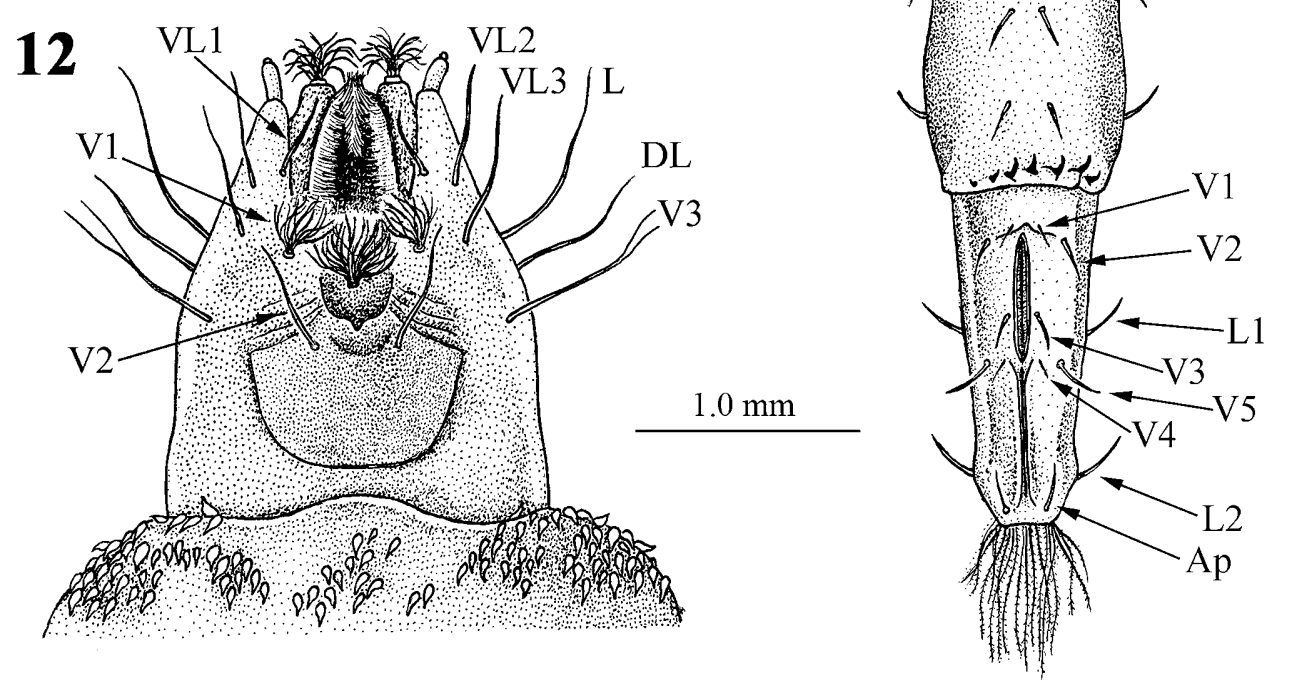

Fig. 10-14: Odontomyia ochropa, larva. 10 - head in dorsal view; 11 - head in lateral view; 12 - head in ventral view; 13 abdominal segments 6-8 in dorsal view; 14 - abdominal segments 6-8 in ventral view. h - hooks, Ad1, Ad2, Ap, Cf1, Cf2, D, Dl, D2, D3, DL, L, L1, L2, Lb1, Lb2, V1, V2, V3, V4 V5, VL1, VL2, VL3 - constant setae. 
dinal anal slit located in basal half of anal segment and occupying about one third of segment length (Fig. 14).

Respiratory system. Dark brown anterior spiracles on sides of thoracic segment 1 relatively small, almost circular, each formed by a low cuticular plate bearing anterior circular stigmatic area with two spiracular slits and a small posterior circle with stigmatic scar. Usually, dorsolateral spiracles placed close to lateral margin of thoracic segment 3 and abdominal segments $1-7$ very small, circular and brown, very probably non-functional. Posterior transverse spiracular opening at apex of anal segment surrounded by coronet of pinnate float hairs. Float hairs arranged in three distinct groups on each dorsal and ventral margin of breathing chamber. Dorsomedian float hairs often somewhat shortened.

Chaetotaxy (for terminology see Rozkošný, 1982). All characteristic setae of head present; general scheme as in other known larvae of Odontomyia. Head capsule virtually without surface hairs (except for conspicuously haired ventral side of genal lobes and anterior margin of ventral opening). Setae flattened, especially in basal half. Labral setae (Lb1, Lb2) short and broadly pinnate (Figs $10,11)$, posterior clypeofrontal setae (Cf2) at level of posterior eye margin with one or 2 branches; anterior clypeofrontal setae (Cf1) simple and slender, about twice as long as Cf2 (Figs 10, 11). Three pairs of setae on ventral side of the head. Setae V2 relatively long and simple, V3 seta long two-branched, V1 seta close to ventral opening, largely fan-like and transverse with its numerous branches, but often almost invisible among marginal hairs of genal lobes (Fig. 12). Arrangement of slender ventrolateral setae as follows: VL1 in middle of genal lobe, VL2 between lateral seta (L) and antenna, VL3 in front of V3 (Figs 11, 12).

Setae on body segments mostly poorly visible, weak and hyaline, though sometimes longer than half of relevant segment. Especially lateral setae often barely distinct among other pubescence. Chaetotaxy of thoracic segment 1 complete: 2 pairs of anterodorsal (Ad) and 3 pairs of dorsal setae (D), all simple; D2 setae shifted anteriorly (Fig. 10). One dorsolateral and ventrolateral seta on each side, both of same length, almost half as long as segment. Ventral side with two-branched outer ventral setae (V2) and simple inner ventral setae (V1) inserted more medially. Dense, short and partly flattened scale-like hairs well developed along anterior dorsal margin of segment, occupying slightly more than medial third. Other pubescence sparse, hyaline, denser only along lateral margins. Setae on thoracic segments 2 and 3 in same position, only anterodorsal setae absent. Dorsal setae in the typical configuration, i.e. D1 and D3 almost in same transverse line and D2 conspicuously shifted towards anterior margin of segments.

Dorsal setae on abdominal segments $1-7$ as in thoracic segments 2 and 3, D2 setae the longest and inserted close to anterior third of segments; D1 short medial pair and inserted at same level as D3, near posterior margin of segments (Fig. 13). Dorsolateral and ventrolateral setae mostly distinct, on each side of abdominal segments, though only very fine; ventrolateral seta inserted near middle of lateral margin and often as long as one third of segment. Two lateral setae, constant in other Odontomyia larvae, are short and virtually indistinct among lateral hairs. Of the 3 pairs of ventral setae, medial pair (V1) inserted near posterior margin, V2 located more laterally and V3 situated above V1 and V2 near anterior margin (Fig. 14). All pairs often only pooly distinct because of additional, sparse and scattered setae developed on ventral surface. Anal segment (= abdominal segment 8) with a pair of long dorsal setae on distal third, 2 long lateral setae on each side (one above middle of segment and second in posterolateral corners) (Fig. 13) and 5 ventral setae (V1 above anal slit, V2 more laterally, V3 at sides of anal slit, V4 at level of distal end of anal slit between anal slit and lateral margin of segment and V5 at same level but more medially) (Fig. 14). Pair of apical setae (Ap) well visible on ventral side of anal segment just above apical coronet. Subapical setae not found.

Measurements. Length 10.2-17.5 mm; maximum width 1.5-3.8 mm. 2 larvae examined.

\section{Puparium}

The puparium is formed from the cuticle of the last larval instar and thus bears all cuticular structures described in larva. The length and maximum width of puparia are the same as in mature larvae. The puparial exuviae are mostly paler than the larvae, and surface cuticular structures (darker plates, transverse rows of spines and often also constant setae) are usually more distinct. In full accordance with the other known Stratiomyini larvae, no pupal structures (prolongation of anterior spiracles or pupal respiratory tubes on abdominal segments) are present on the surface of puparia.

Measurements. Length 27.8-28.5 mm; maximum width 3.8-4.2 mm. 2 puparial exuviae examined.

Material examined. Two larvae and two complete puparial exuviae with associated males (see Singapore under adults) from NMSC.

\section{Biology}

Brunetti (1920) recorded (under $O$. dorsoangulata) one specimen "bred from aquatic larva", which was found at Coimbatore, Madras (India) in October 1913, although no further information was given. Adults were collected, according to the same author, on "chrysanthemums" and Euphorbia in India. Almost 80 years later (1991) larvae were collected in a duck pond near Singapore and a male emerged some days later. One of the authors (D.K.) tried to find the breeding site in 1995 , but the locality had been destroyed.

\section{Odontomyia cyanea Brunetti, 1920 \\ Larva}

Described in detail by Mathur (1933).

Material examined. THAILAND: 4 larvae and 2 puparial exuviae, Larn Sarn National Park, rock-pool on a river bank, 27.iv.1995, 1 đ̊ ex larva 27.iv.1995, 2 \&, ex larvae, 1.v.1995 (D. Kovac) (FSMU), 1 + , ex larva 28.iv.1995, 1, ex larva 2.v.1995, 27 larvae, rock-pool on a river bank, Mae Sa valley near Chiangmai, 7.iv.1998 (D. Kovac) (SMFD). 

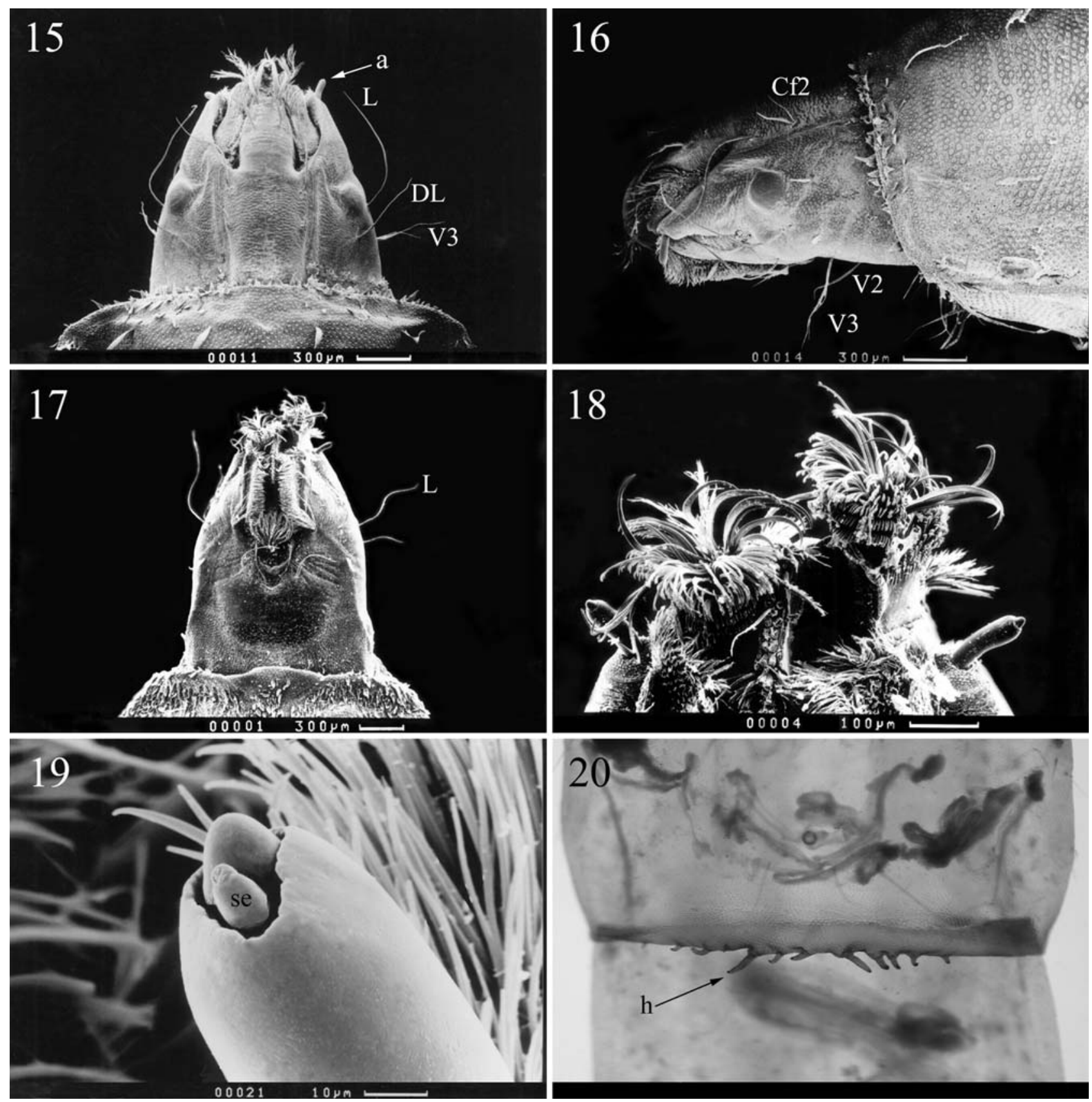

Fig. 15-20: Odontomyia ochropa, larva. 15 - head in dorsal view; 16 - head in lateral view; 17 - head in ventral view; 18 mouthparts in ventrolateral view; 19 - antenna with sensilla; 20 - abdominal segments $4-5$ in ventral view. a - antenna, h - hooks, se - sensilla, Cf2, DL, L, V2, V3 - constant setae.

\section{DISCUSSION}

The female holotype of $O$. ochropa was compared with material from India, Thailand and Singapore, fitting the description of $O$. dorsoangulata. The pair of syntypes of the latter species from Calcutta should be deposited in the Indian Museum, Calcutta. Unfortunately we did not succeed in borrowing these types, but we found several specimens (see material examined) labelled "Calcutta, Indian Museum" in NHMW originating from the type locality, which are unlikely to be part of the type series. After comparison of the holotype female of $O$. ochropa with these specimens, we conclude that both species are identical.

This conclusion is also supported by the fact that Brunetti (1920) mentioned some larval characters of his $O$. dorsoangulata, including "a few short hooks on hind margin of the last five segments, apart from the ultimate segment". The larva of $O$. ochropa cannot be mistaken for any other known Oriental species of the genus owing to the occurrence of transverse rows of spines (hooks) on the posterior margins of abdominal segments $1-7$. Chaetotaxy of the head of $O$. ochropa corresponds to that of the other known Odontomyia larvae, although some setae have a different shape. The most important species- 

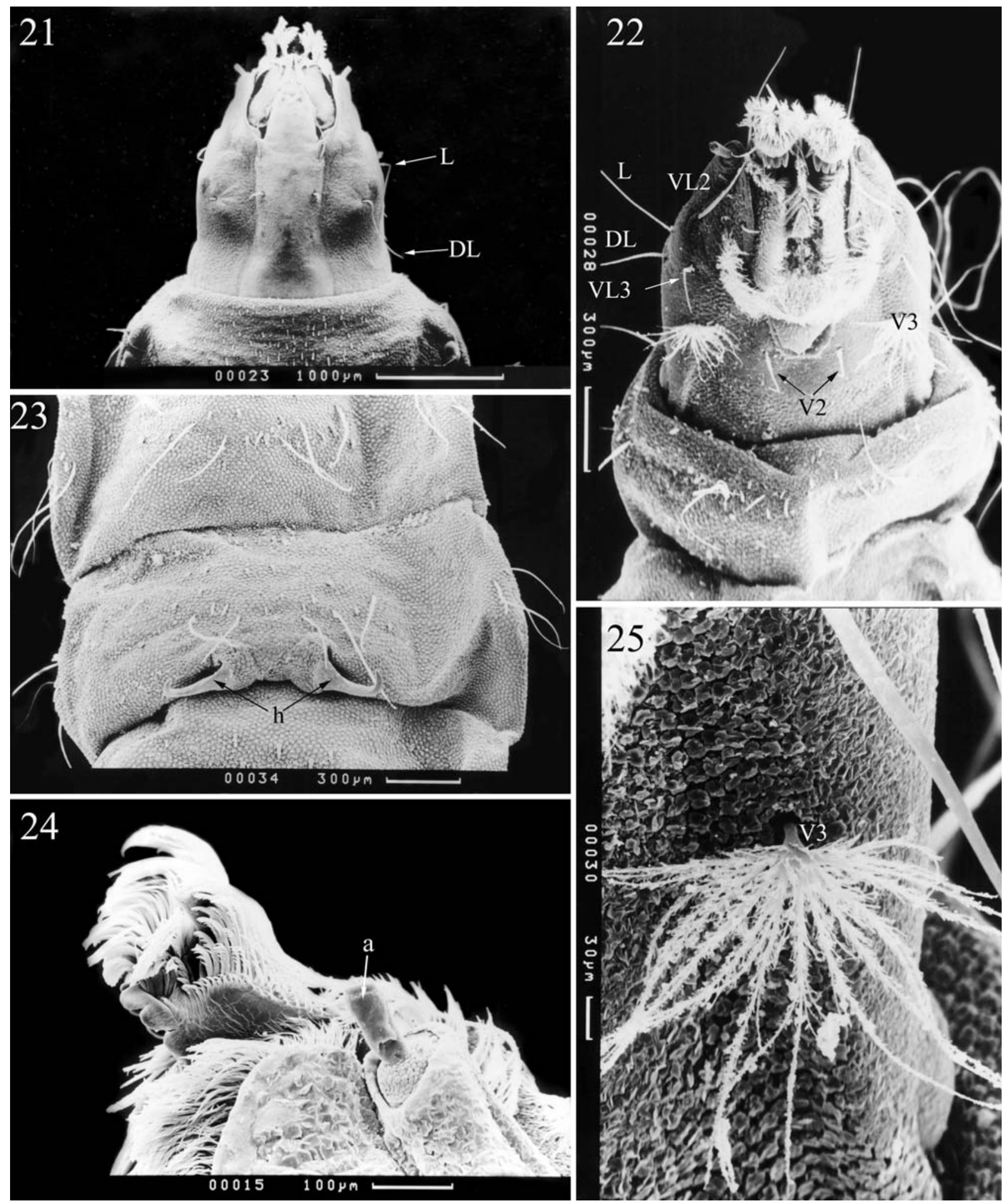

Fig. 21-25. Odontomyia cyanea, larva. 21 - head in dorsal view; 22 - head in ventral view; 23 - second abdominal segment in ventral view; 24 - mandibular-maxillary complex in lateral view; 25 - fan-like seta $\mathrm{V}_{3}$ in detail. a - antenna, h - hooks, DL, L, V2, V3, VL2, VL3 - constant setae.

specific difference is the long V3 with only two branches (Figs 11, 12, 16), this seta being largely fan-like in the other species of Oriental Odontomyia (see Figs 22, 25).

O. ochropa is still treated in the catalogues (cf. Woodley, 2001) as endemic to the Philippines. Our revi- sion shows that this species is in fact widespread from India to the Philippines, including Thailand and Singapore.

We had the opportunity to compare the larva of $O$. ochropa with recently collected larvae of the Oriental $O$. 
cyanea, which have already been described by Mathur (1933). Our SEM micrographs well document a few conspicuous differences: Ventral setae V3 broadly fan-like (Figs 22, 25) and only one pair of strong ventral hooks on abdominal segments 2 and 7 (Fig. 23).

\section{A preliminary key to the Oriental Odontomyia larvae}

Four species of Oriental Odontomyia larvae are described. A brief and very superficial description of the larva of $O$. ochropa is given by Brunetti (1920, under $O$. dorsoangulata) and the species described in detail in the present paper. O. cyanea was described in detail by Mathur (1933) and some diagnostic characters are illustrated here in the SEM micrographs. Descriptions of the Oriental $O$. latitibia and $O$. pulcherrima larvae were published by Rozkošný \& Kovac (1994 and 2001, respectively), who also proposed the first identification key for the known Oriental larvae of the genus.

1 Third ventral seta on head (V3) with 2 branches, posterior margin of abdominal segments 1-7 with transverse rows of ventral spines or hooks........ O. ochropa Thomson, 1869

- Third ventral seta on head (V3) broadly fan-like, pairs of strong ventral hooks developed at most on abdominal seg-

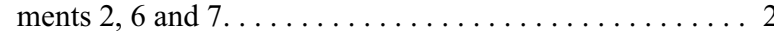

2 Lateral margins of body segments with tuifts of long setae; ventral hooks developed only on posterior margin of abdominal segment 7...... O. pulcherrima Brunetti, 1920

- Lateral margins of body segments without tufts of long lateral setae; ventral hooks developed at least on posterior margin of abdominal segments 2 and $7 \ldots \ldots \ldots \ldots . \ldots 3$

3 Ventral hooks developed on abdominal segments 2, 6 and 7; anal segment about four times as long as broad. ......... ... . . . . . . . . . O. latitibia Rozkošný \& Kovac, 1994

- Ventral hooks developed on abdominal segments 2 and 7; anal segment about twice as long as broad. ............ ................... O. cyanea Brunetti, 1920

ACKNOWLEDGEMENTS. Our thanks are due to R. ContrerasLichtenberg (Vienna), T. Pape (Stockholm, now Copenhagen),
V. Rojanavongse (Department of Entomology, Kasetsart University, Bangkok) and C. Yang (Raffles Museum for Biodiversity Research, National University of Singapore) for providing material for our study. C. Yang and D. Wiwatwitaya (Department of Forestry, Kasetsart University, Bangkok) helped organize the field trips in Singapore and Thailand. Research was supported by the Ministry of Education of the Czech Republic (Programme MSM 0021622416).

\section{REFERENCES}

BRUnetti E. 1920: The fauna of British India, including Ceylon and Burma. Diptera Brachycera. Vol. I. Taylor \& Francis, London, ix $+401 \mathrm{pp}$.

BRUnetTI E. 1923: Second revision of the Oriental Stratiomyidae. Rec. Ind. Mus. 25: 45-180.

MathuR R.N. 1933: Notes on the bionomics of Odontomyia cyanea Brunetti (Diptera: Stratiomyidae). Ind. J. Agric. Sci. 3: 369-376.

LiNDNER E. 1937: Indo-australische Stratiomyiiden (Diptera). Ann. Mag. Nat. Hist. 20: 370-394.

LinDNER E. 1951: Stratiomyiiden von Sumba und Timor (Dipt.). Verh. Naturforsch. Ges. Basel 62: 218-223.

Rozkošný R. 1982: A Biosystematic Study of the European Stratiomyidae (Diptera). Vol. 1. Dr W. Junk, The Hague, 401 pp.

RozkošNÝ R. \& Kovac D. 1994: A new species of Odontomyia Meigen (Insecta: Diptera: Stratiomyidae) from Sabah, Borneo. Raffles Bull. Zool. 42: 859-867.

RozkošNÝ R. \& Kovac D. 2001: New male, larva and puparium of Odontomyia pulcherrima Brunetti (Insecta: Diptera: Stratiomyidae) from the Oriental Region. Raffles Bull. Zool. 49: 101-108.

Thomson C.G. 1869: Kongliga svenska fregatten Eugenies resa omkring jorden under befäl af C.A. Virgin ären 1851-1853. Vol. 2 (Zoologie), 1: Insekter. P.A. Norstedt \& Söner, Stockholm, $617 \mathrm{pp}$.

Woodley N.E. 2001: A World Catalog of the Stratiomyidae (Insecta: Diptera). Backhuys Publishers, Leiden, 473 pp.

Received January 26, 2006; revised and accepted September 7, 2006 